\title{
Flow Characteristics in a Rotating Circular Flume
}

\author{
B. Gharabaghi*,1, C. Inkratas ${ }^{1}$, B.G. Krishnappan ${ }^{2}$ and R.P. Rudra ${ }^{1}$ \\ ${ }^{1}$ School of Engineering, University of Guelph, Guelph, Ontario, N1G 2W1, Canada \\ ${ }^{2}$ National Water Research Institute, Environment Canada, Burlington, Ontario, L7R 4A6, Canada
}

\begin{abstract}
Increased construction activity and associated receiving water concerns in the Greater Toronto Area has prompted this study to advance our knowledge on cohesive sediment transport processes in rivers and lake environments. Flow characteristics in a rotating circular flume at the National Water Research Institute (NWRI), Burlington, Ontario were studied using a computational fluid dynamics (CFD) model. The objective of this study was to use a CFD model to predict the complex 3D turbulent flow characteristics, including the tangential flow velocity distribution, turbulent secondary flow circulation patterns, and the bed shear stress distributions. The numerical model was calibrated using experimental data collected using a Laser Doppler Anemometer for velocity profiles and measurements obtained by a Preston tube for bed shear stress distributions. Tangential velocity profiles and bed shear velocity distributions across the rotating circular flume were used to evaluate the accuracy of the model predictions. When compared with experimental smooth bed shear stress data, the model performed reasonably well for the range of flume speeds examined. The calibrated CFD model was then used for simulating a series of 210 scenarios using varying ring operating speeds over a range of flow depths and bed roughness heights. The numerical simulation results were then used to study the complex 3D turbulent flow conditions in the circular flume at NWRI, including velocity profiles, turbulence characteristics of flow and bed shear stress distributions.
\end{abstract}

Keywords: Rotating circular flume, Bed shear stress, Computational fluid dynamics.

\section{INTRODUCTION}

Urban centers in Ontario are undergoing rapid growth and development. Hundreds of active construction sites in the Greater Toronto Area are at risk of contributing to stormwater runoff pollution and receiving water quality concerns. Excessive turbidity blocks sunlight penetration, reducing photosynthesis by algae and aquatic plants and thus food production for aquatic life [1]. Suspended sediments provide surfaces upon which other contaminants such as heavy metals and chemicals can adsorb [2]. In order to develop a sustainable solution for this problem, industries, governments, and non-government organizations are in the process of evaluating and updating design criteria for controlling sediment transport in urban areas under development [3-5].

Rotating circular flumes consisting of a circular channel and an annular lid rotating in opposite directions are widely used for cohesive sediment transport research [6-13]. As cohesive sediments undergo flocculation when subjected to a flow field and the resulting flocs are susceptible for breakage by moving impellers, straight flumes with pumps to recirculate sediment/water mixture are not suitable for such research [14, 15]. Rotating circular flumes, on the other hand, generate fluid flow by the movement of the physical boundaries and hence are ideally suited for cohesive sediment transport studies. A rotating circular flume at the National Water Research Institute (NWRI) located in Burlington, Ontario is extensively used to study cohesive sediment transport processes in rivers and lake environments.

*Address correspondence to this author at the Water Resources Engineering, Room 2386, Thornborough Building, School of Engineering, University of Guelph, Guelph, Ontario, N1G 2W1, Canada; Tel: (519) 824-4120 ext. 58451; Fax: (519) 836-0227; E-mail: bgharaba@uoguelph.ca
The NWRI flume is $5.0 \mathrm{~m}$ in mean diameter, $30 \mathrm{~cm}$ wide and $30 \mathrm{~cm}$ deep. It rests on a rotating platform, which is 7.0 $\mathrm{m}$ in diameter. The annular lid that fits inside the channel with close tolerance $(1.5 \mathrm{~mm}$ clearance on either side) and makes contact with the water surface is rotated in opposite direction. The maximum rotational speeds of the channel and the lid are $3 \mathrm{rpm}$. The flume is equipped with a Laser Doppler Anemometer for measuring the flow field, and a Malvern Particle Size Analyzer to measure the size distribution of sediment flocs. A modified Preston Tube [16] was used to measure the bed shear stress. Complete details of the flume can be found in [7]. A sectional view of the flume is shown in (Fig. 1).

Earlier hydrodynamic studies carried out in this flume [7, $17,18]$ had shown that the flow fields generated in such flumes is nearly two dimensional and the two-dimensionality of the flows improves when the lid is rotated slightly faster than the flume, and the optimum ratio of the ring speed to the flume speed was determined by minimizing this secondary circulations. In this paper, the predictive capability of a Computational Fluid Dynamics (CFD) model called FLUENT was explored by applying the model to the rotating circular flume of NWRI.

\section{OBJECTIVES}

The objective of this study was to use a CFD model to predict the flow characteristics and a comparison of measured tangential flow velocity distribution and the bed shear stress distributions with the laboratory data in rotating circular flume. The specific objectives of this study was to utilize a CFD model to (1) Minimize the secondary circulation calculation of kinetic energy in the secondary circulation over the operating ring speed range $(-0.67 \mathrm{rpm}$ to $-2.33 \mathrm{rpm}$ with flume channel fixed at $1 \mathrm{rpm}$ ) and varying the bed 


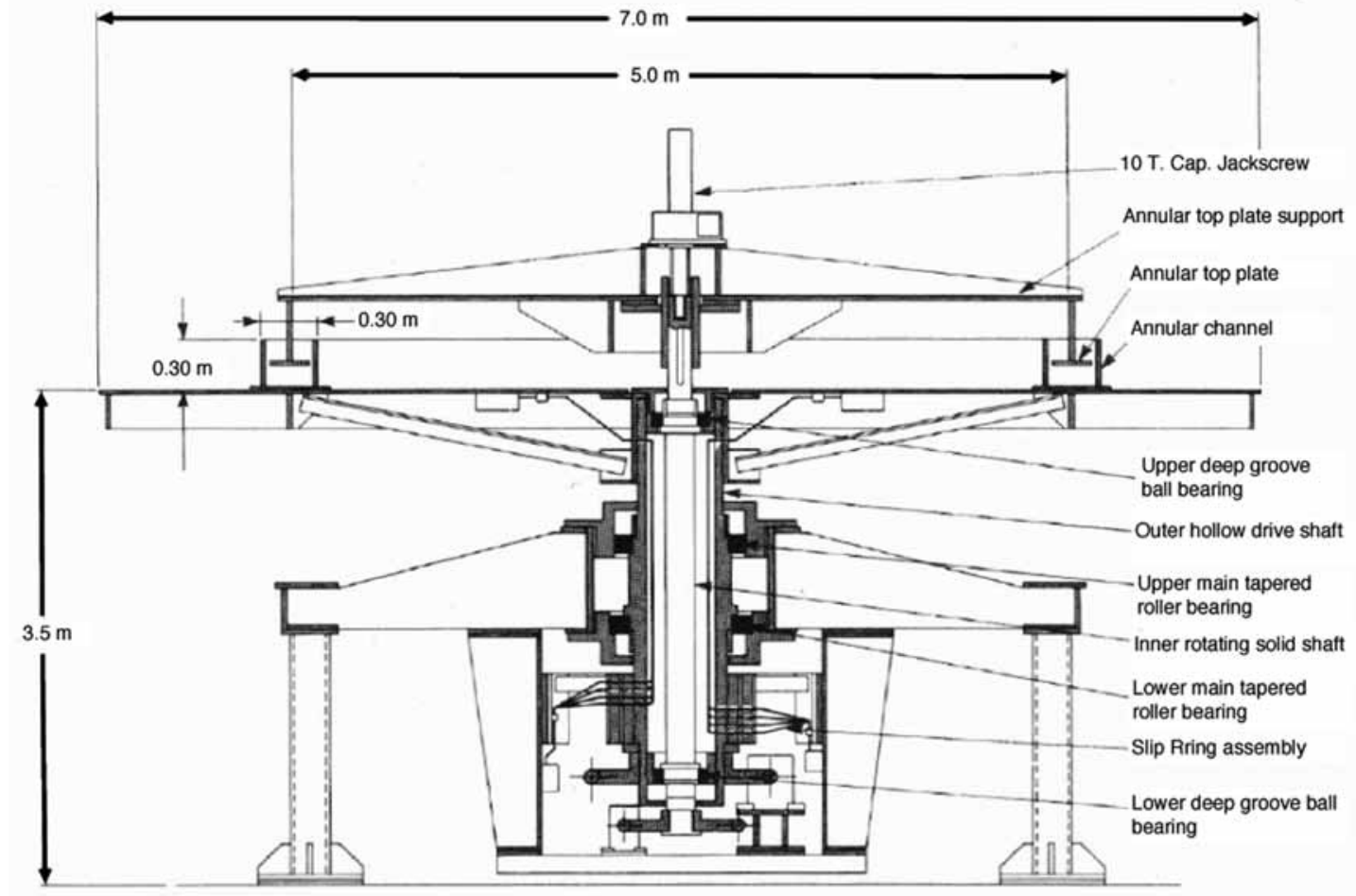

Fig. (1). Sectional View of Rotating Flume Assembly.

roughness $(0,5$ and $10 \mathrm{~mm})$ in order to determine the optimum rotational conditions for various channel depths; and (2) Calculation of bed shear stress - determination of bed shear stress across the flume channel for depths of $10 \mathrm{~cm}$ to $22 \mathrm{~cm}$, bed roughness heights of 0,5 and $10 \mathrm{~mm}$ and a range of ring speeds from $-0.67 \mathrm{rpm}$ to $-2.33 \mathrm{rpm}$ (flume fixed at 1 $\mathrm{rpm})$.

\section{MATERIALS AND METHODS}

FLUENT is a state of the art CFD package which can be used for modelling fluid flow and heat transfer in complex or simple geometries. The complete details can be found in the FLUENT User's Guide [19]. The model was adapted to the flume by considering the flow to be steady, incompressible and fully-turbulent. The turbulence was described using the renormalized theory or RNG k- $\varepsilon$ closure.

\section{MODEL DEVELOPMENT}

The fluid domain was discritized using I-DEAS $11 \mathrm{NX}$ mesh generator software. The version of the FLUENT model used was FLUENT 6.1.22 with the GAMBIT preprocessor. A periodic (cyclic) boundary condition was utilized by considering a small segment of the flume which subtends an angle of 0.01 radians at its centre of curvature. This allowed for a denser meshed section since the use of computer memory was minimized while maintaining an acceptable model run time.

\section{BOUNDARY CONDITIONS}

The GAMBIT CFD preprocessor was used to import the finite element mesh and set wall boundary conditions. The four boundary conditions that were set included: a) the flume walls, b) the flume bed, c) the flume top ring, and d) the nonexistent cross-sectional walls which are required for the use of the cyclic boundary condition. Boundaries a) and b), together, make up the flume channel. The walls and bed were treated separately in order to set the bed roughness differently from the flume walls for representation of varying bed materials. The flume bed and walls were assigned an angular momentum (absolute, rotating wall). Once the boundaries of the model were set, the flume was imported using FLUENT 6.1.22 to perform the CFD analysis. The fluid properties was set as water $\left(\rho=1000 \mathrm{~kg} / \mathrm{m}^{3}\right.$ and $\left.v=0.001 \mathrm{~kg} / \mathrm{m} \cdot \mathrm{s}\right)$. The model was run with a gradually increasing viscous model approach for higher numerical stability.

\section{MODEL CALIBRATION}

The numerical model was calibrated using the experimental data obtained by Krishnappan [7]. Tangential veloc-

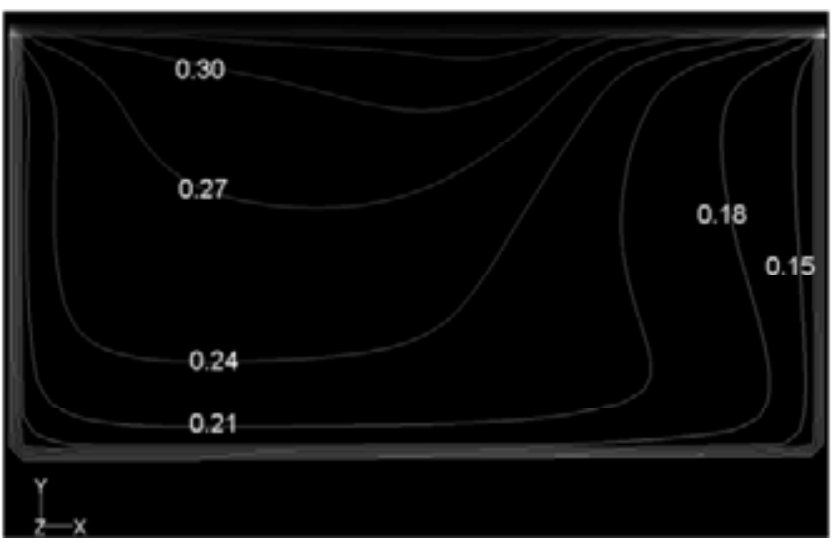

Fig. (2). Tangential isovels $(\mathrm{m} / \mathrm{s})$ for a flume speed of $1 \mathrm{rpm}$, ring speed of $-1 \mathrm{rpm}$ and a flow depth of $15.5 \mathrm{~cm}$ predicted by the FLUENT model. 


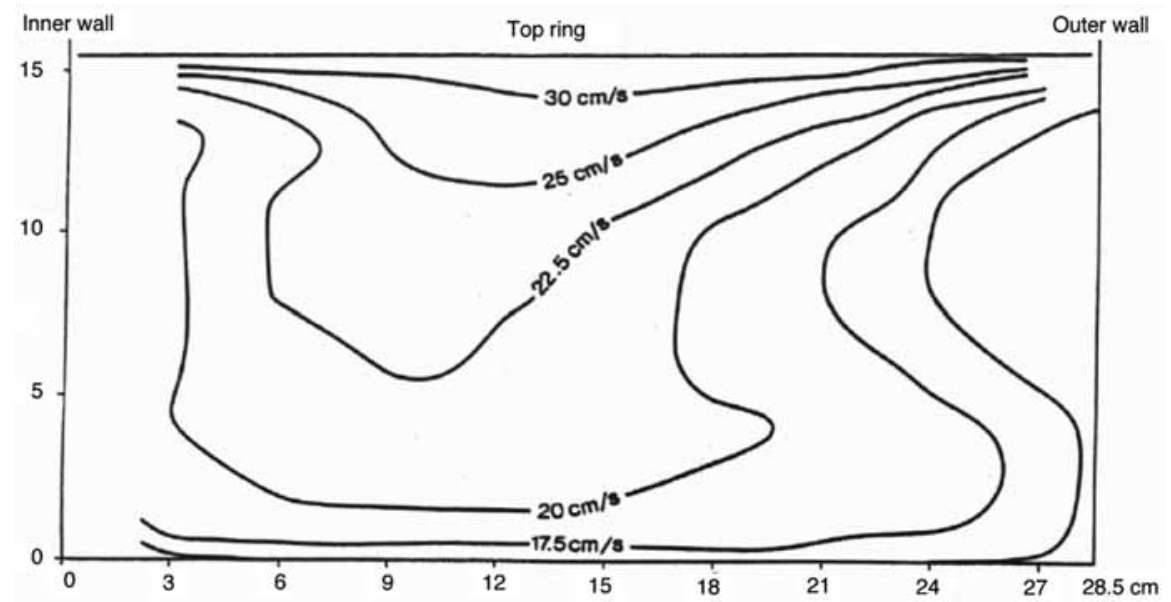

Fig. (3). Tangential isovels for a flume speed of $1 \mathrm{rpm}$, ring speed of $-1 \mathrm{rpm}$ and a flow depth of $15.5 \mathrm{~cm}$ collected experimentally by Krishnappan [7].

ity profiles and bed shear velocity distributions across the rotating flume were used to evaluate the accuracy of the model predictions. Using a rotational flume speed of $1 \mathrm{rpm}$ and ring speed of $-1 \mathrm{rpm}$ with a flow depth of $15.5 \mathrm{~cm}$, the numerical model was used to calculate the tangential velocity profile. Fig. (2) provides the isovels of tangential velocity calculated by the model. Fig. (3) shows the experimental data collected by Krishnappan [7] using identical operating conditions. In comparison to the experimental data, the calibrated numerical model predicted the tangential velocity profile and the velocity contour pattern with less than approximately $15 \%$ error (spot check comparison of Fig. 2 and 3).

\section{COMPARISON OF BED SHEAR STRESS PREDIC- TIONS WITH MEASURED DATA}

The numerical model of the rotating flume was used to simulate several operating speeds $(-0.67,-1.00,-1.33,-1.67$,
-2.00 and $-2.33 \mathrm{rpm}$ ) for the channel while keeping the ring speed at the optimum level as determined by the laboratory experiments (ratio between the ring speed to flume speed held at 1.17). The flow depth for these runs was maintained at $12 \mathrm{~cm}$ and a zero roughness height (smooth bed). The bed shear velocities across the flume are calculated using:

$U^{*}=\sqrt{\frac{\tau}{\rho}}$

where $U^{*}$ is the shear velocity in $\mathrm{m} / \mathrm{s}, \tau$ is the bed shear stress in $\mathrm{Pa}$ and $\rho$ is the density of water in $\mathrm{kg} / \mathrm{m}^{3}$.

The shear velocity curves calculated by FLUENT can be seen in (Fig. 4) along with the corresponding experimental data points for the specific flume and ring speed combinations. The agreement between the predicted distributions and the measured ones is reasonable, although the model predictions are somewhat skewed towards the outer wall, espe-

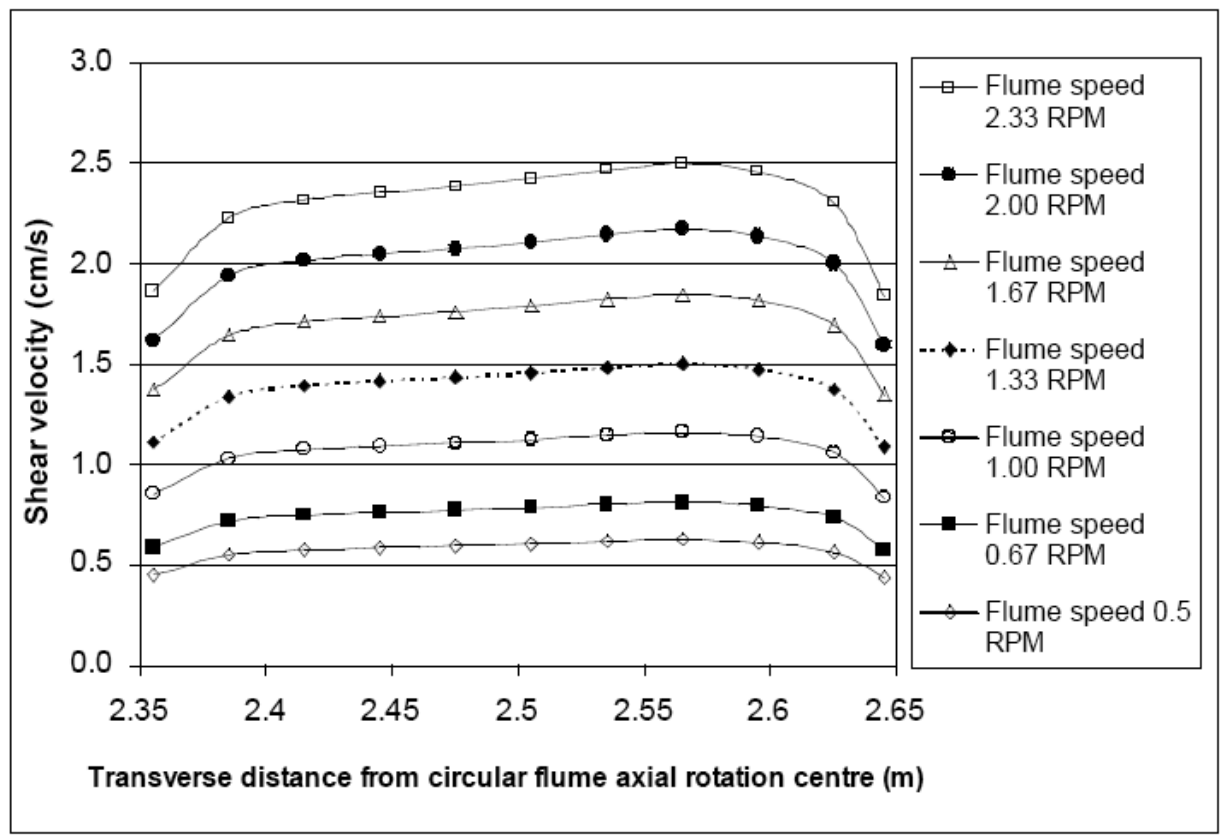

Fig. (4). FLUENT predicted shear velocity distributions as a function of flume speed (Nf) for a flow depth of $12 \mathrm{~cm}$ and a smooth bed (ratio of ring speed to flume speed is 1.17 ). 
cially for higher flume speeds. For lower speeds, the skewness is not pronounced, and the model predictions agree with the measured distributions well. Overall, the model predictions can be considered as satisfactory.

\section{RESULTS AND DISCUSSION FOR NUMERICAL SIMULATION SCENARIOS}

\section{Calculation of Mean Bed Shear Velocity with Varying Flume Operating Conditions}

Two-hundred and ten hypothetical operating scenarios for the rotating circular flume at NWRI were numerically simulated using I-DEAS $11 \mathrm{NX}$ and the FLUENT 6.1.22 CFD code with the GAMBIT preprocessor. Flume models with flow depths of $10 \mathrm{~cm}$ to $22 \mathrm{~cm}$ were simulated using increments of $2 \mathrm{~cm}$ with the process described in the following section. The scenarios included: 1) A range of ring operating speeds $(-0.67,-1.00,-1.33,-1.67,-2.00$ and $-2.33 \mathrm{rpm})$ while the flume channel to ring speed was held constant at 1.17 ; 2) A range of bed roughness heights $(0,2.5,5.0,7.5$ and $10.0 \mathrm{~mm}$ ); and 3) A range of flow depths (10, 12, 14, 16, 18,20 , and $22 \mathrm{~cm}$ ). The range of ring operating speeds was applied to the range of flow depths for each of the bed roughness heights, thus creating 210 scenarios. Several general trends can be seen from the mean bed shear velocity results. These are as follows:

1. With an increase in bed roughness height, bed shear velocity increases,

2. With an increase in flume and ring speed, bed shear velocity increases and

3. With an increase in flow depth, bed shear velocity decreases.

Fig. (5) shows the relationship between the relative speed between the flume and the ring and the mean bed shear velocity for a bed roughness of $10 \mathrm{~mm}$. The results in this fig- ure indicate that the effect of flow depth on bed shear velocities is minor for channel depths between 12 and $22 \mathrm{~cm}$.

For the cases examined, the bed shear velocity shows a linear relationship with the relative speed of the flume assembly. Such a result is in accordance with earlier measurements in rotating circular flumes [20, 21].

\section{Kinetic Energy in the Secondary Circulation}

Controlling the strength of the secondary circulation and thus, the transverse bed shear stress distribution is important for applications in which the circular flume is used as a device in erosion and deposition experimentation [17]. To optimize the ring to flume operating speed ratio, which in turn minimizes the secondary circulations, a number of calculations with a fixed flume speed $(1 \mathrm{rpm})$ and a range of ring speeds $(-0.67,-1.00,-1.33,-1.67,-2.00$ and $-2.33 \mathrm{rpm})$ and bed roughness heights $(0,5$ and $10 \mathrm{~mm})$ have been made using the numerical model. Each run is characterized by the turbulent kinetic energy, $\mathrm{E}_{\mathrm{c}}$, in the vertical and tangential directions, defined as:

$E_{c}=\frac{1}{A} \int_{A} \frac{1}{2}\left(V^{2}+W^{2}\right) d A$

where $\mathrm{A}$ is the cross-sectional area in $\mathrm{m}^{2}, \mathrm{~V}$ is the tangential velocity in $\mathrm{m} / \mathrm{s}$ and $\mathrm{W}$ is the vertical velocity in $\mathrm{m} / \mathrm{s}$.

Fig. (6) shows the kinetic energy of the secondary circulation plotted against the range of ring operating speeds for the different bed roughness heights for a flow depth of 10 $\mathrm{cm}$. Figures for flow depths of $12 \mathrm{~cm}$ to $16 \mathrm{~cm}$ are not provided since the results are similar to that of (Fig. 6) although the ring to flume speed ratio varies for each depth to minimize the kinetic energy.

For smooth channels with depths of $15.5 \mathrm{~cm}$, the minimum kinetic energy occurs at the ring to flume ratio of 1.17 .

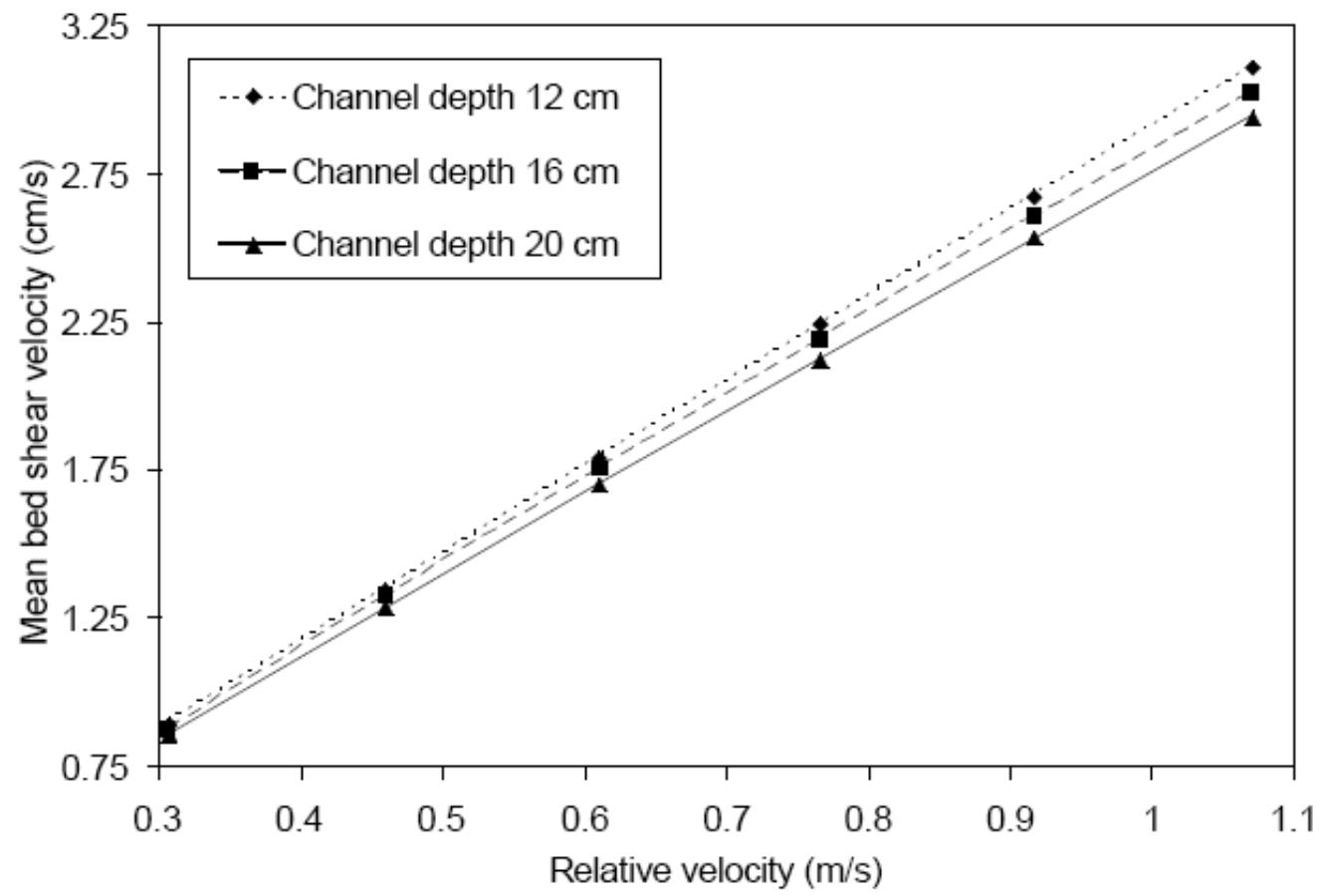

Fig. (5). Mean shear velocity for varying flow depths and a rough bed $(10 \mathrm{~mm})$. 


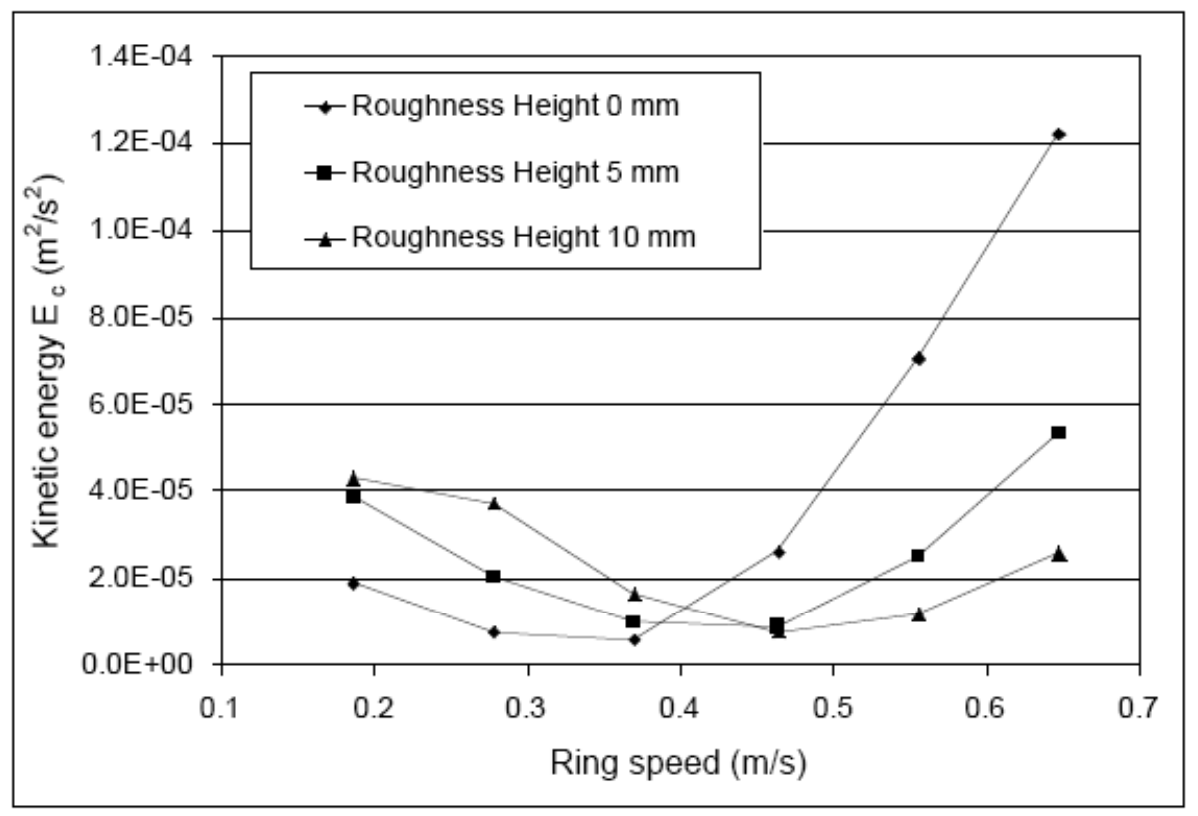

Fig. (6). Kinetic energy, $E_{c}$ in secondary circulation with flow depth $10 \mathrm{~cm}$ and fixed flume speed $(-0.27 \mathrm{~m} / \mathrm{s})$.

However, with increasing roughness, the ring speed must be increased in order to keep the kinetic energy in the secondary circulation to a minimum (approximately 1.55 to 1.65 for 5 $\mathrm{mm}$ bed roughness and 1.65 to 1.75 for $10 \mathrm{~mm}$ bed roughness).

For lower ring to flume speed ratios, the kinetic energy in the secondary circulation remains fairly constant for each of the different roughness values. A distinct rise in energy is present when the ring has a rotational speed of $0.4 \mathrm{~m} / \mathrm{s}(1.4$ ring to flume speed ratio). To generalize for bed depths from $18 \mathrm{~cm}$ to $22 \mathrm{~cm}$, the ring to flume speed ratio should be no greater than 1.4 to minimize secondary circulation for bed roughness heights from 0 to $10 \mathrm{~mm}$.

\section{Secondary Circulation Profiles}

Examination of velocities in the vertical and tangential directions have shown secondary circulation patterns when varying the flume properties and operating conditions. The channel speed was fixed at $1 \mathrm{rpm}$ for the model runs.

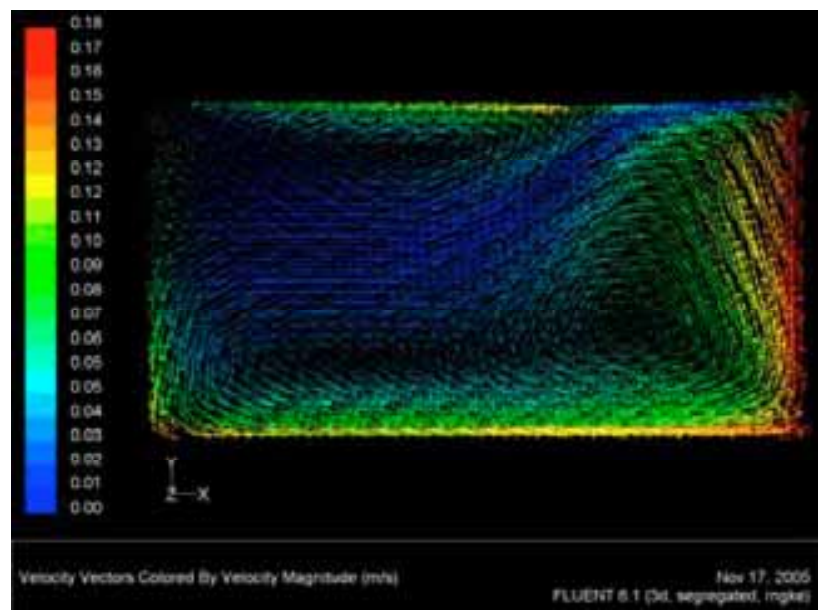

Fig. (7). Secondary flow circulation pattern for a ring to flume speed ratio of 1.00 , channel depth of $15.5 \mathrm{~cm}$ and a smooth bed.
Figs. (7, 8 and 9) show the secondary circulation in a cross-section of the rotating circular flume with respective speed ratios of $1.00,1.17$ and 1.33. The optimum ring to flume speed ratio was 1.17 and this can be seen by comparison of the figures. For a ring to flume ratio of 1.00 (Fig. 7), a large vortex can be seen along the outer wall of the flume (right hand side of the figure) which impacts the kinetic energy present in the fluid leading to increased bed shear stress. Fig. (8) presents the optimum speed ratio of 1.17 and shows a reduced vortex still in approximately the same vicinity as (Fig. 7) along with reasonably low velocities. When the ring to flume ratio is increased from 1.17 to 1.33 , as in (Fig. 9), the vortex is remains stationary, but velocities are increased in the cross-section which also leads to a rise in kinetic energy.

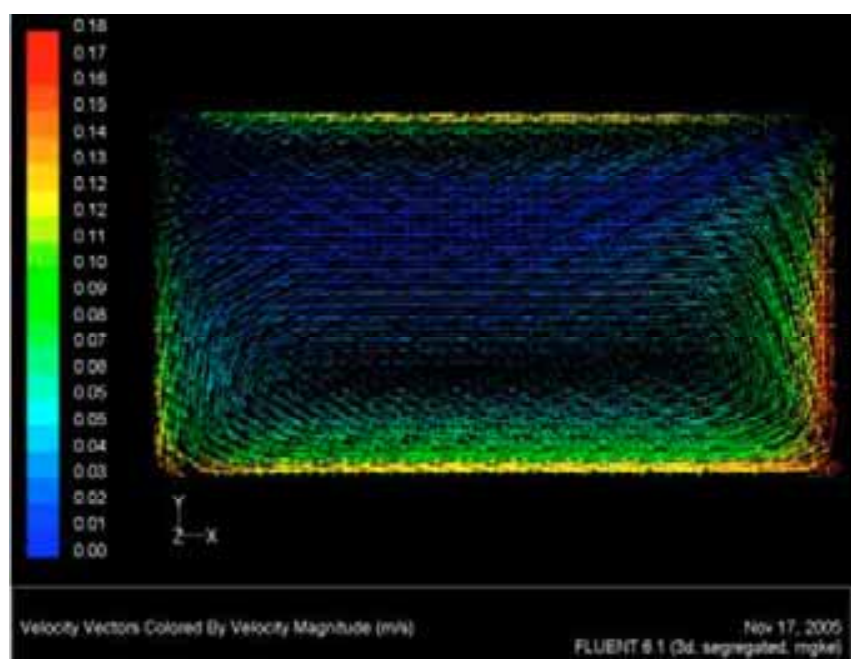

Fig. (8). Secondary flow circulation pattern for a ring to flume speed ratio of 1.17 , channel depth of $15.5 \mathrm{~cm}$ and a smooth bed.

The secondary circulations described above (Figs. 7, 8, and 9) show the optimum ring to flume speed ratio occurs at 1.17 . 


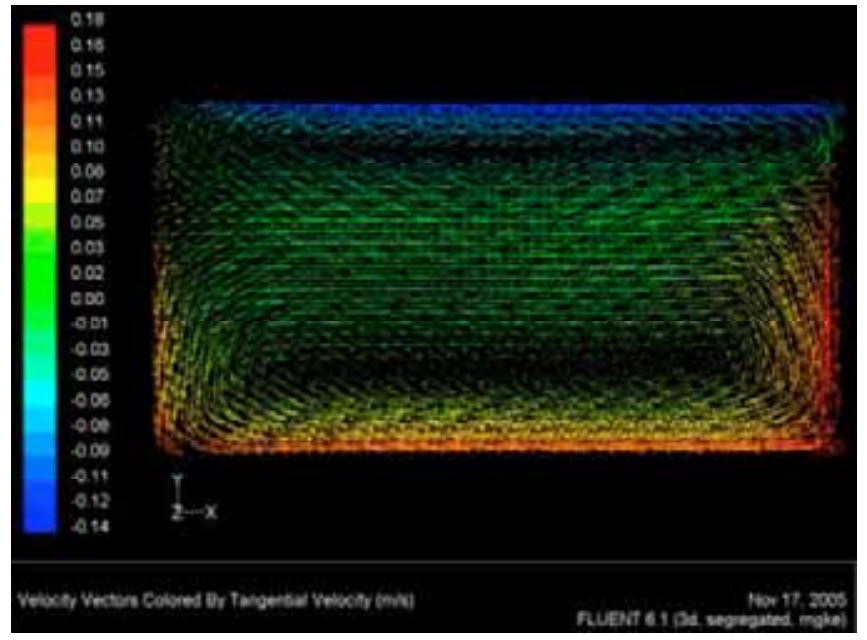

Fig. (9). Secondary flow circulation pattern for a ring to flume speed ratio of 1.33 , channel depth of $15.5 \mathrm{~cm}$ and a smooth bed.

\section{CONCLUSIONS}

This study focuses on complex 3D turbulent flow characteristics in a rotating circular flume at the National Water Research Institute (NWRI) in Burlington, Ontario, Canada. Flow velocities in the rotating circular flume at NWRI was measured using a Laser Doppler Anemometer simulated using the Computational Fluid Dynamic code, FLUENT. The calibrated numerical model was used to run a series of 210 scenarios using varying ring operating speeds over a range of flow depths and bed roughness heights. When compared with experimental smooth bed shear stress data, the model performed reasonably well for the range of flume speeds examined. The numerical model predicted tangential velocity contour patterns with less than $15 \%$ error.

The kinetic energy found in the secondary circulation, as calculated by CFD model, were in agreement with the laboratory experiment data and the velocity profiles also corresponded well with the data. The calculated kinetic energy of the secondary circulations for various flow scenarios was used as a criterion to determine the optimum ring to flume speed ratio. The optimum ring to flume speed ratio that minimized the kinetic energy of the secondary circulations was approximately 1.2. However, this optimum value was seen to increase slightly with bed roughness and decrease with channel depth (range from 1.1 to 1.3).

Mean bed shear velocities produced by the model were examined for a constant ring to flume ratio of 1.2 over a range of speeds. As expected, it was found that bed shear velocity increased as bed roughness and ring speed were increased and that there was a linear relationship between mean bed shear velocity and relative velocity of the ring and flume.

\section{ACKNOWLEDGEMENTS}

The authors would like to acknowledge the financial support of Environment Canada and of the Natural Sciences and Engineering Research Council of Canada (NSERC) which provided the research grant in support of this project.

\section{REFERENCES}

[1] W. E. Henley, M. A. Patterson, R. J. Neves, and D. A. Lemly, "Effects of sedimentation and turbidity of lotic food webs: A concise review for natural resource managers", Reviews in Fisheries Science, vol. 8, pp. 125-139, 2000.

[2] S. Clark, R. Pitt, R. Field, E. et al. "Annotated bibliography of urban wet weather flow literature from 1996 through 2002", U.S. Environmental Protection Agency, Urban Watershed Management Branch, Edison, NJ, USA, 2003.

[3] A. Bradford, and B. Gharabaghi, "Evolution of Ontario's stormwater management planning and design guidance", Water Quality Research Journal of Canada, vol. 39, pp. 343-355, 2004.

[4] B. Gharabaghi, A. Fata, T. Van Seters, et al. "Evaluation of sediment control pond performance at construction sites in the Greater Toronto Area", Canadian Journal of Civil Engineering, vol. 33, pp. 1335-1344, 2006.

[5] B. Gharabaghi, R. P. Rudra, and P. K. Goel, "Effectiveness of vegetative filter strips in removal of pollutants from overland flow", Water Quality Research Journal of Canada, vol. 41, pp. 275-282, 2006.

[6] D. I. Graham, P. W. James, T. E. R. Jones, J. M. Davies, and E. A. Delo, "Measurement and prediction of surface shear stress in annular flume", Journal of Hydraulic Engineering, vol. 118, pp. 12701286, 1992.

[7] B. G. Krishnappan, "Rotating Circular Flume", Journal of Hydraulic Engineering, vol. 119, pp. 758-767, 1993.

[8] E. Partheniades, and J. F. Kennedy, "Depositional behaviour of fine sediment in a turbulent fluid motion", Proc. $10^{\text {th }}$ Conference on Coastal Engineering, London, England, vol. 2, pp. 723-742, 1996.

[9] P.W. James, T. E. R. Jones, D. M. Stewart, "Numerical and experimental studies of annular flume flow", Appl Math Model, vol. 20, pp. 225-231, March 1996.

[10] R. Booij, "K- $\varepsilon$ Model Computations of the Flow in Rotating Annular Flumes", in XXVII IAHR Congress, Water for a Changing Global Community, 1997, pp. 10-15.

[11] M. G. Skafel, and B. G. Krishnappan, "Laboratory investigation of depositional characteristics of mud from an inland harbour using a rotating circular flume", Water, Air and Soil Pollution, vol. 112, pp. 1-19, May 1999.

[12] Z. Yang, A. Baptista, and J. Darland, "Numerical modeling of flow characteristics in a rotating annular flume', Dynamics of Atmospheres and Oceans, vol. 31, pp. 271-94, January 2000.

[13] M. Cantero, S. Mangini, F. Pedocchi, Y. Nino, and M. Garcia, "Analysis of flow characteristics in an annular flume: Implications for erosion and deposition of cohesive sediments," in World Water and Environmental Resources Congress, 2004, pp. 2610-2619.

[14] Y. L. Lau, I. G. Droppo, and B. G. Krishnappan, "Sequential erosion/deposition experiments - demonstrating the effects of depositional history on sediment erosion", Canadian Water Resources Journal, vol. 35, pp. 2767-2773, 2001.

[15] B. G. Krishnappan, "Erosion behavior of fine sediment deposits", Canadian Journal of Civil Engineering, vol. 31, pp. 759-766, 2004.

[16] M. Jin, "Boundry shear stress measurements by two tubes", Journal of Hydraulic Research, vol. 33, pp. 385-395, 1995.

[17] O. Peterson, and B. G. Krishnappan, "Measurement and analysis of flow characteristics in a rotating circular flume", Journal of $\mathrm{Hy}$ draulic Research, vol. 32, pp. 483-494, 1994.

[18] B. G. Krishnappan, and P. Engel, "Distribution of bed shear stress in rotating circular flume", Journal of Hydraulic Engineering, vol. 130, pp. 324-331, 2004.

[19] Fluent Inc. "Fluent 6.1.22 User's Guide", Lebanon, New Hampshire, USA, 2003 [Online]. Available: http://www.fluent.com/ software/fluent/index.htm [Accessed Oct 31, 2005].

[20] E. Partheniades, J. F. Kennedy, R. J. Etter, and R. P. Hoyer, "Investigation of the depositional behavior of fine cohesive sediments in an annular rotating channel", Hydrodynamics Lab. Rep. No. 96, Massachusetts Institute of Technology, Cambridge, Massachusetts, 1966. 
[21] B. G. Krishnappan, P. Engel, and R. Stephens, "Shear velocity distribution in a rotating flume", NWRI Contribution No. 94-102,
National Water Research Institute, Environment Canada, Canada Centre for Inland Waters, Burlington, Ontario, Canada, 1994. 